\title{
Trends in epidemiology of diabetes mellitus in Greece. Review of the major epidemiological studies
}

\author{
Chariclia V Loupa*, Sofia Kalantzi and Alkiviadis Maris \\ Demetrios Voyatzoglou Diabetic Foot Outpatient Clinic, Amalia Fleming Hospital Unit, Athens, Greece
}

\begin{abstract}
Objective: A literature review of major publications was conducted to describe the epidemiology and trends over time of diabetes mellitus in Greece.

Results: Although studies differ regarding methodology (self-reporting or data recording versus blood glucose measurements and OGTT), there is an increase in the prevalence of diabetes in the Greek population. In the Attica region, prevalence increased from 2,4\% in 1974 to 9,5\% (self-reporting studies) or 11,6\% (blood glucose measurements and OGTT) in 2006. Regarding rural population, where prevalence was almost negligible (1,5\%) during 1988-1993, there was a dramatic increase (approximately 11,7\% during 2003-2005), to become equal to urban population. This change is similar to the trends worldwide. The cause of this increase is lifestyle change, with a consequent decrease in the physical activity, junk food, and obesity. Prevalence is higher in lower socioeconomic status. Intervention is important to decrease diabetes incidence by modifying modern lifestyle.
\end{abstract}

\section{Introduction}

Diabetes mellitus (DM) currently constitutes a global epidemic. It is estimated that $6 \%$ of the worldwide adult population suffers from DM [1]. The increased prevalence of DM worldwide has significant socioeconomic consequences.

Diabetes, ranked fifteenth in the global list of causes of death in 1990, was upgraded to ninth position in 2010 [2]. At the same time, the International Diabetes Federation (IDF) estimates that total global healthcare spending on DM more than tripled over the period 20032013 as a result of increases both in the prevalence and per capita spending [3].

The increase in prevalence of DM is rapid, and IDF [4] estimates that people with diabetes, which were 350 million in 2011, will more than double and reach 552 million by 2030 [2].

A similar increase in the prevalence of DM is observed in Greece. In the Attica region, the prevalence increased from 2.4\% in 1974 to $9.5 \%$ in $2006[4,5]$. In this paper, we present and analyze the most important epidemiological studies concerning the prevalence of DM in Greece and outline the possible causes of this increase.

\section{Data for Greece}

\section{Methodology of studies}

The studies of prevalence of DM in Greece, belong to two methodologically different categories, and therefore there are concerns in comparing and extracting cumulative data.

A. Self-reporting, in which an individual participates by answering to the question whether he/she is suffering from DM, or medical records are reviewed.

B. Studies based on blood sugar measurements and the performance of an oral glucose tolerance test (OGTT).
It is reasonable that in the second category, studies are more sensitive, including cases hitherto undiagnosed. Therefore, in these studies the estimated prevalence is expected to be higher.

It should be noted that the prevalence and incidence of type $1 \mathrm{DM}$ are easier to measure reliably than type $2 \mathrm{DM}$, type $1 \mathrm{DM}$ being a disease with acute symptoms that cannot remain undiagnosed for a long time.

\section{Prevalence}

Urban and semi-urban population: The first major study in the area of Greece is the study of Aegaleo, an area of the Attica region, by Katsilambros et al. [4]. It belongs to the self-reporting studies. A team of researchers moved door-to-door in the Aegaleo district (mostly urban area) in 1974, asking for diagnosed diabetes cases. This study estimated the prevalence in the urban population as $2.4 \%$ for 1974 . The same team repeated the study fifteen years later in the same area, using the same methodology, providing comparable results. They estimated the prevalence as $3.1 \%$ in 1990 (an increase of $30 \%$ over 15 years in this urban population).

Next, there is Salamis, also part of the Attica region, study, by Ghikas et al. [5]. It concerned the mostly urban area of Salamis Island, and it also belongs to the self-reporting studies. On Election Day, voters were questioned if they suffer from DM. The researchers estimated the prevalence as $8.2 \%$ in 2002 (i.e., it almost tripled in 12 years' time, compared to the study of Aegaleo). This study was repeated by the same research team using identical methodology, in the same area, ensuring

Correspondence to: Chariclia Loupa, Amalia Fleming General Hospital Sporadon 2, Chalandri, GR-15231, Greece, Tel: +30-213-2003398; E-mail: Ch-loupa@hol.gr

Key words: diabetes mellitus, epidemiology, incidence, prevalence, Greece

Received: December 03, 2017; Accepted: December 14, 2017; Published: December 18, 2017 
comparability. Estimated prevalence was 9.5 for 2006 (15\% increase in 4 years). Note that this number was comparable to the $9.6 \%$ reported prevalence of DM in the US in 2005 [6].

In 2001, the Attica study was conducted by Stephanadis et al. [7]. It belongs to the second group of study groups, by carrying out measurements. Therefore, the results are expected higher than the previous ones due to methodology. The population of Attica $(80 \%$ urban $/ 20 \%$ rural) was studied. DM prevalence was found to be $6.9 \%$ for 2001 , highest in men ( $8.0 \%$ vs. $5.8 \%$ of women). Study was repeated after five years (2006), by the same investigators, in the same area, and with the same methodology. The prevalence almost doubled (11.6\%), with male superiority ( $12.8 \%$ vs. $10.4 \%$ for women). Figure 1 illustrates the upward trend in the prevalence of DM in the Attica region.

The study of Thessaly region by Koukoulis et al. [8] concerns the period 2003-2005. It involved carrying out glucose measurements, and additionally performing an OGTT, which further increased the sensitivity of the study and therefore higher prevalence rates are expected. The population of Thessaly, $60 \%$ urban and $40 \%$ rural, was studied.

The average prevalence of DM in the period 2003-2005 was $11.77 \%$, similar to the Attica study as mentioned above over a comparable period. It is notable that this number was similar to the $14.3 \%$, calculated for the US in 2012 [3].

Rural population: One of the first studies of the rural population in the village of Spili, Crete [9], examined the patients' medical records. The prevalence of DM in the period 1988-1993 was found to be $1.52 \%$, i.e., significantly less than that of the urban population.

Similar studies were conducted by Papazoglou et al. (1993-1995) in northern Greece (Prefecture of Evros, Prefecture of Serres, Prefecture of Kilkis, Prefecture of Imathia and Prefecture of Rhodopi) [10-14]. They used data extracted from medical records and local pharmacies' archives. In this area of mixed urban and rural population, during the period 1990-1995 the prevalence was found to be 1.6-2.02\% (i.e. 1.6 $1.82-2.02-1.57$ and $1.83 \%$ in the above counties, respectively).

The lower prevalence of DM in the rural population could be attributed, among other factors, to a healthier diet (Mediterranean

\section{DM Prevalence (\%)}

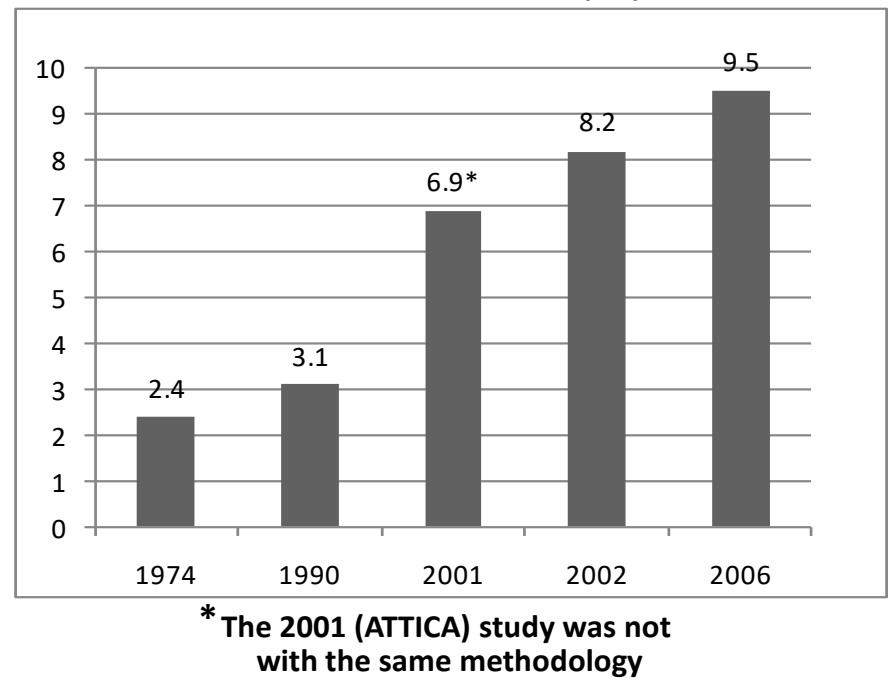

Figure 1. Prevalence of diabetes mellitus in the Attica region over time. diet), more physical activity, and perhaps underdiagnosis.

However, the Argolid study by Melidonis et al. [15] in 2002 overturns the scene. It was carried out in a rural population of 3 villages in Argolida in Peloponnese region, and belongs to the second category of studies (the one with measurements), with the addition of OGTT (so higher prevalence is expected). The prevalence of DM was found to be $7.8 \%$ in 2002, comparable to the 2001 findings from Attica urban population, which had a comparable methodology. Therefore, there is a considerable increase in the prevalence of DM in the rural population, which now was found similar to the urban population.

The increase in prevalence does not guarantee a similar rise of the incidence of DM. It could be partly attributed to better care and followup of diabetic individuals, which consequently increases life expectancy of diabetic patients [15].

However, the dramatic increase in diabetes in rural areas, where it did not consist a health problem in the past, is also proven in other studies. In the above mentioned Thessaly survey in 2003-2005 [8], a partial analysis of the results showed an increased incidence of DM in rural areas. Figure 2 illustrates the huge (10-fold) overtime increase in the prevalence of DM in the rural population of Greece.

\section{Incidence}

Type 2 diabetes mellitus: In the Attica study [16], which continued until 2012, there was an increase in the incidence of DM. The 5-year incidence, from $5.5 \%$ in the period 2002-2007, amounted to $6.6 \%$ over the period 2007-2012. Since the proportion of type $1 \mathrm{DM}$ in the population is very low [ $1 \%$ of diabetics in the Salamis study [5]], we can assume that this increase in incidence is attributed to type $2 \mathrm{DM}$.

Type 1 diabetes mellitus: Type 1 DM, because of acute symptomatology, cannot remain undiagnosed for a long time. Consequently, its incidence is easier to be calculated reliably than that of Type 2 DM.

There are three studies about the incidence of type $1 \mathrm{DM}$.

The study by Dakou et al. [17] estimated the incidence of type 1 diabetes mellitus at 10.0/100,000 per year in Athens, and in rural areas as $4.2 / 100,000$ per year (under-double).

The study of Bartsokas et al. [18] calculated the average annual incidence of type $1 \mathrm{DM}$ as $9.7 / 100,000$ in the Athens area, relatively constant over time, a number similar to the Dakou study.

In the period 1990-2001, Mamoulakis et al. [19], estimated the incidence of type1 DM at 6.1/100.000 per year in the region of Crete. When comparing the individual data, the average annual prevalence was estimated at 4.9 in the six-year period 1990-1995 (similar to Dakou) and increased to 7.2/100.000 in the six-year period 1996-2001. From the above three studies, we see a lower incidence of type $1 \mathrm{DM}$ in the rural population than in the urban people, but with upward trends over time.

\section{Absolute numbers}

Based on the calculated prevalence and with the extrapolation to the entire population of Greece, the number of people with diabetes is estimated approximately as 250,000 in 1974 [4] and nearly 800,000 in 2006 [5], i.e., it has more than tripled over 30 years. According to Eurostat [20], on January 1, 2017, the population of Greece was $10,757,300$. By multiplying the number of the Greek population by the 
prevalence of $11 \%$ from the year 2006, the number of diabetics for 2017 reach the number of $1,184,000$ people.

The calculated absolute number of people with diabetes in Greece over time is shown in Figure 3.

\section{Possible explanation of the increase of DM cases}

As mentioned above, studies reported an increase of DM prevalence over time. Some of the possible causes of this increase are mentioned by Colagiuri et al. [21]:

- Increase in population screening - earlier diagnosis (refers to selfreported studies)

- Increased life expectancy - aging population

- Reduction of mortality in diabetic individuals

- Change of criteria, lower age limits of studied population

If we look at the possible causes in more detail:

The Attica, Thessaly and Argolida studies [7,8,15], were performed with blood glucose measurements and with OGTT, and reported that about $30 \%$ of diabetics were not hitherto diagnosed. Because of the increased awareness of the population in recent years, which resulted in increased screening and earlier diagnosis, it would have been reasonable a "factitious" increase in the prevalence of DM.

Increased life expectancy and the aging of the population also lead to an increase in the proportion of diabetic individuals, as diabetes increases with age. The Attica study [16], founded that the 10-year

\section{DM Prevalence (\%)}

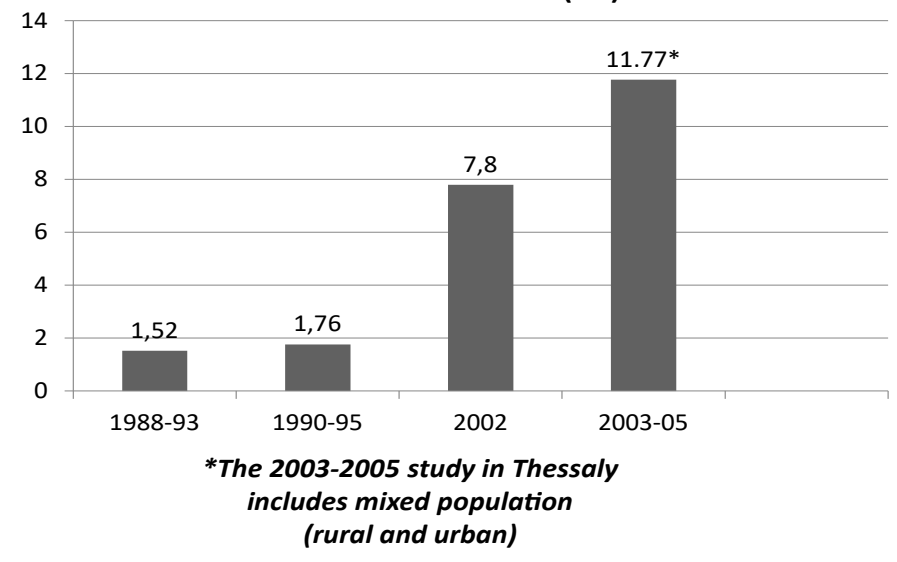

Figure 2. Prevalence of diabetes mellitus in Greek rural population over time.

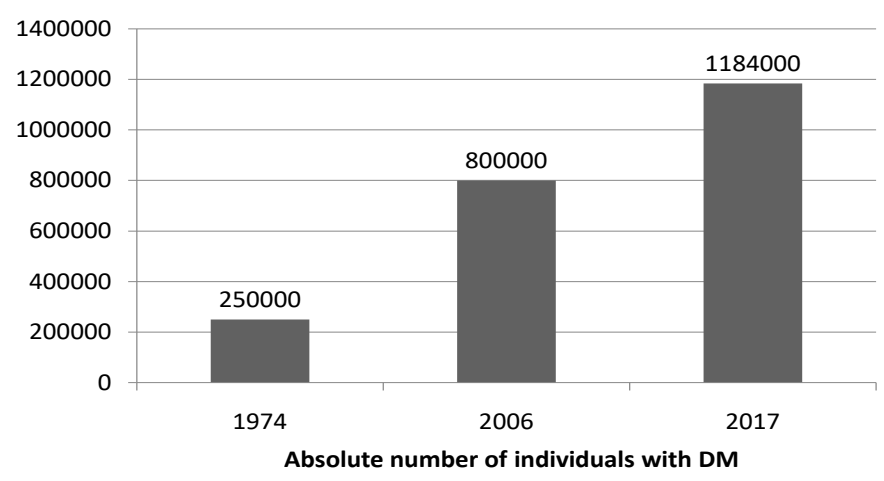

Figure 3. Estimated absolute numbers of individuals with diabetes mellitus over time. incidence of DM was $10.6 \%$ in subjects aged $35-44$, while in people $\geq$ 75 years it was significantly higher (29.2\%). The Argolid study [15], founded a substantially higher prevalence in subjects aged 71-80 years ( $14.2 \%$ in males) compared to people $31-40$ years of age ( $8.5 \%$ in men).

In the Thessaly study [8], the incidence in the $70-80$ age group was $37.5 \%$, while in the $40-49$ age group it was only $8.37 \%$. The reduction in the mortality of diabetic individuals due to better access to medical care is also a fact.

The scenario of the change of the criteria is not applicable here because almost all the studies (apart from the oldest ones) were carried out under the current criteria. All of the above, however, are confounding factors that alter the composition of the population and the proportion of diabetic individuals. They do not consist real causes of DM increase.

What are the real causes then? The real reason of rising prevalence of DM is the socio-economic development of the past decades, which has resulted in dramatic lifestyle change:

- Sedentary life - lack of exercise

- Junk food

- Obesity

Sedentary lifestyle preveils, at the expense of physical activity. In the Attica study [7], 30.4\% of men and $29.4 \%$ of women who were physically active at the beginning of the study (2001) adopted sedentary lifestyle later on (2006). The Mediterranean diet has been increasingly replaced by junk food. These two factors result in increase of obesity. In the Salamis study [5], the prevalence of obesity in 2002 was $17.9 \%$, while in 2006 it was $21.1 \%$, with an average weight gain of $2 \mathrm{~kg}$ in 4 years.

A sad confirmation of the harmful effects of obesity on the incidence of diabetes is the example of World War II. A study in the Netherlands [22] showed a significant reduction in the prevalence of diabetes (140 new cases in the Amsterdam health system in 1940, compared to only 3 in 1945. Number of visits resumed at 112 in 1949).

Also, food shortages in Japan have dramatically reduced the incidence of the DM, which has risen again since 1947 [23]. The same phenomenon was observed in Germany during World War I [24-26].

The significant increase of the incidence and prevalence of DM in Greece poses a great challenge for public health policy and should be accompanied by preventive measures.

\section{Limitations}

The present study is not a systematic review. However we sought to include all significant relevant papers. The accuracy and reliability of the data presented reflect the quality of the original research, with some inherent limitations of the self-reporting studies.

\section{Declarations section}

- Ethics approval and consent to participate: Not applicable

- Consent to publish: Not applicable

- Availability of data and materials: Not applicable

- Competing interests: the authors declare no competing interests

- Funding: None 
- Authors' Contributions: C.L. conceived the study, researched and retrieved the reviewed studies. All authors drafted the manuscript and revised it critically. All authors read and approved the final manuscript.

\section{References}

1. Mayor S (2006) Diabetes affects nearly 6\% of the world's adults. BMJ 333: 1191. [Crossref]

2. International Diabetes Federation (2011) Global Burden: Prevalence and Projections, 2011 and 2030. http://www.diabetesatlas.org/content/diabetes-and-impairedglucosetolerance.

3. Dwyer-Lindgren L, Mackenbach JP, van Lenthe FJ, Flaxman AD, Mokdad AH (2016) Diagnosed and Undiagnosed Diabetes Prevalence by County in the U.S., 1999-2012. Diabetes Care 39: 1556-1562. [Crossref]

4. Katsilambros N, Aliferis K, Darvirib C, Tsapogas P, Alexiou Z, et al. (1993) Evidence for an Increase in the prevalence of Known Diabetes in a sample of an Urban Population in Greece. Diabet Med 10:87-90. [Crossref]

5. Gikas A, Sotiropoulos A, Panagiotakos D, Pastromas V, Paraskevopoulou E, et al. (2008) Rising prevalence of diabetes among Greek adults: Findings from two consecutive surveys in the same target population. Diabetes Res Clin Pract 79: 325 329. [Crossref]

6. Centers for Disease Control and Prevention (2005) National Diabetes Fact Sheet: General Information and National Estimates on Diabetes in the United States. US Department of Health and Human Services, CDC, Atlanta, GA, 2005. http://www.cdc. gov/diabetes/pubs/pdf/ndfs_2005.pdf.

7. Panagiotakos DB, Pitsavos C, Chrysohoou C, Skoumas I, Stefanadis C (2009) Prevalence and five-year incidence (2001-2006) of cardiovascular disease risk factors in a Greek sample: the ATTICA study. Hellenic J Cardiol 50: 388-395. [Crossref]

8. Tsirona S, Katsaros F, Bargiota A, Polyzos SA, Arapoglou G, et al. (2016) Prevalence and determinants of type 2 diabetes mellitus in a Greek adult population. Hormones (Athens) 15: 88-98. [Crossref]

9. Lionis CD, Sasarolis SM, Koutis AD, Antonakis NA, Benos A, et al. (1996) Measuring the prevalence of diabetes mellitus in a Greek primary health care district. Fam Pract 13: 18-21. [Crossref]

10. Papazoglou N, Manes C, Soulis K, Kontogiannis I, Skaragas G, et al. (1995) Epidemiology of Diabetes in Greece. VI. Serres Prefecture [article in Greek]. Hellenic Diabetological Chronicle 8: 132-137.

11. Papazoglou N, Manes C, Gkirtzis I, Christakidis D, Nikolaidis I, et al. (1993) Epidemiology of Diabetes in Greece. II. Evros county [article in Greek]. Hellenic Diabetological Chronicle 6: 134-140.
12. Papazoglou N, Manes C, Milarakis D, Satsoglou A, Soulis D, et al. (1993) Epidemiology of Diabetes in Greece ??I. Kilkis county [article in Greek]. Hellenic Diabetological Chronicle 6: 141-145.

13. Papazoglou N, Skaragas G, Hatzipetrou A, Maras P, Papadeli E, et al. (1994) Epidemiology of Diabetes in Greece IV. Imathia county [article in Greek]. Hellenic Diabetological Chronicle 7: 41-44.

14. Papazoglou N, Manes C, Marinos E, Papadeli E, Soulis K, et al. (1995) Epidemiology of Diabetes in Greece V. Rodopi county [article in Greek]. Hellenic Diabetological Chronicle 8: 126-131.

15. Melidonis A, Tournis S, Kompoti MG, Lentzas IL, Roussou VR, et al. (2006) Increased prevalence of diabetes mellitus in a rural Greek population. Rural Remote Health 6: 534. [Crossref]

16. Koloverou E, Panagiotakos DB, Pitsavos C, Chrysohoou C, Georgousopoulou EN, et al. (2014) 10-year incidence of diabetes and associated risk factors in Greece: the ATTICA study (2002-2012). Rev Diabet Stud 11: 181-189. [Crossref]

17. Dacou-Voutetakis C, Karavanaki K, Tsoka-Gennatas H (1995) National data on the epidemiology of IDDM in Greece. Cases diagnosed in 1992. Hellenic Epidemiology Study Group. Diabetes Care 18: 552-554. [Crossref]

18. Bartsocas CS, Dacou-Voutetakis C, Damianaki D, Karayanni CH, Kassiou C, et al (1998) Epidemiology of childhood IDDM in Athens: trends in incidence for the years 1989-1995. Eurodiab ACE G1 Group. Diabetologia 41: 245-246. [Crossref]

19. Mamoulakis D, Galanakis E, Bicouvarakis S, Paraskakis E, Sbyrakis S (2003) Epidemiology of childhood type I diabetes in Crete, 1990-2001. Acta Paediatr 92: 737739. [Crossref]

20. Eurostat, European Commission (2017) Population change - Demographic balance and crude rates at national level. http://ec.europa.eu/eurostat. Accessed 08.11.2017.

21. Colagiuri S, Borch-Johnsen K, Glümer C, Vistisen D (2005) There really is an epidemic of type 2 diabetes. Diabetologia 48: 1459-1463. [Crossref]

22. Hermanides J, Belkhazi L, Michels RP, Hoekstra JB (2008) Lower incidence of type 2 diabetes mellitus with changes in lifestyle: clues from World War II. Ned Tijdschr Geneeskd 152: 2415-2417. [Crossref]

23. Goto Y, Nakayama Y, Yagi T (1958) Influence of the World War II food shortage on the incidence of diabetes mellitus in Japan. Diabetes 7: 133-135. [Crossref]

24. Beckert W (1940) Ueber die Haufigkeit des Diabetes und die Auswirkungen der Lebensmittelrationierung auf dessenVerauf. Muenchen med Wchnschr 11: 1333.

25. Gottstein A, Umber F (1916) Diabetes und Krieg. Deutsche med Wchnschr 43: 1309.

26. Singer R, Elias H (1920) Diabetes mellitus und Kriegskost in Wien. Deutsche med Wchnschr 46: 561 .

Copyright: (C2017 Loupa CV. This is an open-access article distributed under the terms of the Creative Commons Attribution License, which permits unrestricted use, distribution, and reproduction in any medium, provided the original author and source are credited. 